\section{APROXIMACIONES CONCEPTUALES: COMUNICACIÓN POPULAR, COMUNICACIÓN COMUNITARIA Y COMUNICACIÓN \\ ALTERNATIVA}

\section{Felipe Navarro Nicoletti}

(IIDyPCa/UNRN/ANPCyT), San Carlos de Bariloche, Río Negro, Argentina.

fnavarro.nicoletti@gmail.com
CONCEPTUAL APPROXIMATIONS:

\section{POPULAR COMMUNICATION, COMMUNITY COMMUNICATION AND ALTERNATIVE COMMUNICATION}

\section{Paula Rodríguez Marino}

(UNRN/CIEDIS), Viedma, Río Negro, Argentina. prmarino@unrn.edu.ar

Para citar este artículo:

Navarro Nicoletti, F. \& Rodríguez Marino, P. (2018). Aproximaciones conceptuales: comunicación popular, comunicación comunitaria y comunicación alternativa. Commons. Revista de Comunicación y Ciudadanía Digital, 7(2), 37-66

http://dx.doi.org/10.25267/COMMONS.2018.v7.i2.02

Fecha de recepción: 12/07/2018. Fecha de aceptación: 22/10/2018

\section{Resumen}

En este artículo se realizará una reconstrucción de ciertas líneas conceptuales y de algunos de los autores que consideramos más relevantes para establecer una aproximación hacia las definiciones de la comunicación popular, alternativa y comunitaria. Estos conceptos han tenido un largo recorrido desde finales de los años $70^{\prime}$ hasta la actualidad, desvelando continuidades y rupturas. En el siguiente trabajo buscaremos reconstruir dichos conceptos desde los principales autores que creemos necesarios para acercarnos a la pluralidad de definiciones y significaciones de los campos citados.

\section{Palabras clave}

Comunicación popular, comunicación comunitaria, comunicación alternativa

\section{Abstract}

In this article there will be realized a reconstruction of certain conceptual lines and of some of the authors that we consider to be more relevant to establish an approximation towards the definitions of the popular, alternative and community communication. These concepts have had a length crossed from ends of the years '70 up to the present, unveiling continuities and breaks. In the following work we will look to reconstruct the mentioned concepts from the principal authors that we believe necessary to approach at the plurality of definitions and significances of the mentioned fields.

Keywords

Popular communication, community communication, alternative communication 


\section{Introducción}

El objetivo principal será realizar una reconstrucción de ciertas perspectivas teóricas, establecer similitudes, contradicciones y acuerdos de algunos de los autores que consideramos más necesarios para aproximarnos hacia las definiciones de la comunicación popular, alternativa y comunitaria. Se trata de una búsqueda conceptual y la comparación, en algunos sectores del campo intelectual, entre las definiciones de la comunicación popular, comunitaria y alternativa, remarcando los antecedentes más destacados. El trabajo realizado es de corte exploratorio, teniendo en consideración la escasez de otros trabajos que aborden la temática. Debido a la amplitud del tema decidimos realizar un recorte guiándonos a partir de los autores que tuvieron mayor difusión y circulación académica en Argentina, además de representatividad en el campo teórico.

Pretendemos comparar y diferenciar estos conceptos para aportarlos en futuros estudios y debates. La puesta en cuestión de estas categorías y su desbroce remite al debate y apropiación de los estudios en Comunicación y Cultura en América Latina según diferentes corrientes y perspectivas.

Creemos que el anclaje de la investigación en los conceptos de comunicación popular, alternativa y comunitaria pueden ser útiles, con posterioridad, para indagar sobre la relación entre la comunicación comunitaria y lo territorial, la comunicación alternativa y el campo ideológico y la comunicación popular y la construcción de identidades. A lo largo del trabajo, iremos desentrañando diversos autores latinoamericanos que remiten a cada eje conceptual: un primer apartado referido a "lo popular", un segundo que expone "lo alternativo" y un tercero sobre "lo comunitario", finalizando en un cuarto con el objetivo de dar cuenta sobre la variabilidad y polisemia de sus usos. Existe una variedad de concepciones y significaciones respecto a las tres nociones que, en algunos autores, conllevan la 
indistinción o la superposición. Uno de los autores que ha abordado los problemas de la indiferenciación entre las categorías abordadas, Washington Uranga (2016) afirma que "pensar y analizar los procesos comunicacionales desde la perspectiva de transformación, demanda recoger lo mejor de nuestras tradiciones en comunicación popular, alternativa, comunitaria, poniéndolas en conjunción con aquellas configuraciones que atiendan a la comunicación como industria" (Uranga, 2016: 61).

Si bien Uranga (2016) da cuenta de lo comunitario, lo popular y lo alternativo como tres categorías de mayor utilización pero que, al final de la transformación y dinamización social, es menester verlas en conjunto. Finalmente, el autor va a dar cuenta de categorías individuales y colectivas condicionadas entre sí.

Entre otros autores, Larisa Kejval (2009) indica que hay medios (radiofónicos) en los cuales lo que predomina es la auto caracterización de forma simultánea como comunicación popular y alternativa. Otra forma de imbricación surge de la conjunción entre comunicación popular y comunitaria. A continuación abordaremos estas cuestiones.

\section{Antecedentes y debates sobre "lo popular"}

Para marcar nuestra posición dentro del subcampo de la comunicación popular y dar cuenta de su relación con lo masivo -no como una degradación-, nos alejamos de la posición de Pierre Bourdieu (1999), que expone que no puede haber nada por fuera del capital dominante, ya que la distribución del "capital legítimo" es desigual y genera posiciones dentro del campo. Teniendo esto en cuenta, nos posicionamos en el enfoque crítico de Grignon y Passeron (1989) que señalan a la noción de gusto (gusto de necesidad) expuesta por Bourdieu (Op.cit.) como errónea, argumentando que él mismo comete la falta de aplicar la perspectiva de análisis poniendo en el centro de la escena a la cultura dominante a la vez que 
aplica las formas de dominación al resto con un criterio de carácter dominante. Sin embargo, la posición de que lo popular no se encuentra siempre en un plano de resistencia, sino que existe, en palabras de Grignon y Passeron (Op.cit.), un "gusto popular" a pesar de la dominación e incluyen necesidades y demandas de los sectores populares.

Freire es otro antecedente sobre lo popular que sienta las bases para unificar lo popular con lo masivo, pero toda forma de descodificación de los medios de comunicación debe ser parte de la lucha por la concienciación de los códigos dominantes que afectan a la vida cotidiana. De esta forma, para Freire las masas populares (no usa aquí el término "audiencia") son productores, una vez que haya sido efectivo ese proceso de ruptura de los códigos del opresor y que permitirá al oprimido iniciarse en un camino hacia la lucha revolucionaria. En este sentido, los objetivos de Freire están marcados como los de Mattelart (2014) y Graziano (1980) por la disputa ideológica, como parte de la lucha por la toma del poder de las masas populares. A su vez, se observa que a diferencia de los escritos de otros autores como Mata (1988) y Martín Barbero (1987) privilegiamos el uso del término masas populares, a los de audiencias o públicos ${ }^{1}$. En adelante se explicita cómo Mata (Op.cit.) utiliza el término público e identidades, a diferencia de Freire que en "Pedagogía del Oprimido" y en "Educación como práctica para la libertad" (1965) lo hace considerando la oposición hegemonía/contrahegemonía pero la propone en términos más afines a la época, como opresores y oprimidos (2005: $105-107 ; 112 ; 114)$. Las masas populares son el resultado y la construcción del proceso dialógico en oposición al anti dialógico de los opresores. La noción de comunicación como comunión aparece con frecuencia en los autores que se refieren a lo popular. También en aquellos que podrían considerar una noción de comunicación alternativa como Schmucler (1982). La propuesta de este autor es la de conservar la barra "/" para mantener la diferenciación pero, a la vez, la unión entre los dos campos considerando que la perspectiva de la Comunicación y Cultura por la "y" los termina por separar.

1. Martín Barbero puede ser considerado por algunos como parte de los estudios culturales latinoamericanos que, así como los estudios culturales británicos, mantiene disputas con la Economía Política de la Comunicación, por ejemplo, con Mattelart, respecto del excesivo centramiento en la subjetividad de las audiencias, en la reelaboración simbólica y en la escasa atención a los factores económicos y de producción de los medios masivos. 
María Cristina Mata (1988) indaga lo popular desde las audiencias radiales en la provincia de Córdoba (Argentina) y la configuración de sus públicos. Es así como la autora retoma el análisis desde la relación emisor-receptor, productos y prácticas sociales. La autora rescata la identidad de lo popular desde lo masivo y las prácticas sociales generadas desde los medios de comunicación. Para Mata la creación de proyectos populares, desde dicho sector social, está en diálogo con el aparato de poder social y las condiciones de vida que generan. Esta conceptualización de lo popular es posible en tanto utiliza el concepto de identidad y evita una división tajante entre lo masivo y lo popular, que estaba presente tanto en la concepción de la dialogicidad como condición para la hominización como en la dualidad opresor y oprimido. Posteriormente, Freire asume dinámicas más complejas a la luz de nuevas revalorizaciones sobre aquellos elementos de lo masivo que constituyen lo popular y al considerar que no todo proceso revolucionario requiere, exclusivamente, de las operaciones de la conciencia. Así como observamos en Althusser (Dubravcic, 2002) que bajo los procesos inconscientes de interpelación ideológica no puede analizarse un proceso o mecanismo social por fuera de ella. Las transformaciones epistemológicas y geopolíticas en el llamado Tercer Mundo también llevan a Dubravcic Alaiza (Op.cit.) a referirse a la dominación/subordinación como parte de un mismo proceso, abandonando la lógica oposicional del opresor y del oprimido, lo que permite revalorizar, como lo planteaba Mata, los proyectos basados en las identidades populares en las cuales confluyen lo popular y lo masivo.

Martha Dubravcic Alaiza (2002) parte de la denominación "comunicación popular alternativa": en primer lugar desde el cambio social, luego desde el esquema "dominación/subordinación" y en tercer lugar desde las mediaciones sociales y culturales, centrándose en el tercer eje propuesto. Para transmitir este posicionamiento, la autora retoma referentes como Mattelart, Martín Barbero, Althusser, Bajtín, Freire, Eco, De Certeau y Gramsci para dar cuenta del concepto de hegemonía. 
Teniendo en cuenta que "lo popular" se establece en un proceso histórico y social, Dubravcic expone un recorrido que parte de los años 60' con la comunicación conductista de Lasswell, donde lo popular se establecía como subcultura (inferior), pasando por los medios de comunicación en clave desarrollista (que la autora identificaría con Mattelart) y la formación de la hegemonía gracias al trabajo de los medios de comunicación como aparatos ideológicos del Estado como afirma Althusser. A partir de esto, Bajtín es referencia obligada en las reflexiones sobre la represión y exclusión contra la cultura popular, tratando de recuperar las señas de identidad y posibilitando la línea que marca a lo popular gestado desde lo masivo (Dubravcic, 2002).

Una cuestión que los planteamientos de Bajtín van a quebrar es la concepción de la comunicación, tanto popular, como alternativa y comunitaria en términos de codificación, decodificación, mensajes y canales. Esta cuestión es bastante evidente en el caso de la propuesta de Freire y complejiza la forma a través de la cual las masas populares se reconocen a sí mismas a partir de la reintegración de temas y problemas planteados en la codificación, reapropiados y reinsertos en "la situación existencial" (Freire, 2005: 106).

Desde la misma línea histórica, Dubravcic retoma a Freire para explicar las mediaciones sociales y culturales de la comunicación popular que ponderan el díalogo como instrumento de liberación. Esta nueva posición activa del receptor también se observa desde Umberto Eco y su concepto de "apropiación" de los actores sociales, o en De Certeau en tanto estrategias y tácticas de los actores ante esos mensajes apropiados.

Bajo la premisa de retomar lo popular configurado desde lo masivo, la autora retoma los conceptos de hegemonía y de subalternidad de Gramsci, resumiendo el proceso según Martín Barbero: 
Lo popular se configura entonces como ese lugar desde el que se hace posible históricamente abarcar y comprender el sentido que adquieren los procesos de comunicación y nos hallamos en proceso de construcción de un nuevo modelo de análisis que coloca a la cultura como mediación social y teórica de la comunicación con lo popular. (Dubravcic. 2002: 48)

Superando la concepción purista de lo popular, se retoma dicho concepto como la construcción desde diversas disciplinas y autores. La comunicación popular define desde la transformación social de los actores y la diversidad cultural como matriz fundamental.

Néstor García Canclini (1983) parte de la gran cantidad de definiciones de "lo popular". Expone los "prejuicios" y se propone analizar los paradigmas de lo popular más influyentes en las ciencias sociales y en las políticas culturales de América Latina (p.153). Con la misma lógica que recorren la mayoría de los autores aquí presentados, García Canclini también realiza un recorrido histórico de "lo popular", desde el campo político, cultural y social. En cuanto a lo político, liga "lo popular" a "lo tradicional" o rural y luego a la idea nacional populista desde la figura estatal. Con respecto al campo cultural, García Canclini divide la bibliografía en la vertiente omnipotente de la dominación ideológica (en los 60' con la creación de grandes medios de comunicación), la capacidad de resistencia política de las clases subalternas (avance de movimientos políticos alternativos desde el concepto de hegemonía), consumo y formas propias de organización de los sectores populares respecto a la resolución de sus necesidades (1983: 159). La veta social de "lo popular" la define desde la organización y la réplica sociopolítica sobre el análisis de las resistencias de las clases subalternas (1983: 162). 
García Canclini (Op.cit.) concluye afirmando que la redefinición de "lo popular" se juega en el campo de la estructura de las contradicciones y la localización social de los conflictos (lo popular ante las desigualdades), el carácter integral de la transformación social y sujetos sociales (haciendo foco en las clases sociales y separándose de la teoría marxista).

Por otro lado, Jesús Martín Barbero ha sido parte influyente de la mayoría de los autores aquí expuestos acerca de la definición de varios conceptos actualmente utilizados, en este caso nos enfocaremos en la construcción que realiza el autor de "lo popular". En su emblemático libro "De los medios a las mediaciones" (1987), Martín Barbero comienza diciendo que "no se puede pensar a lo popular al margen de lo masivo" (1987: 10). El autor instala la idea de que no se puede pensar "lo popular" en el ámbito de la cultura en un sentido romántico, al margen de lo construido hegemónica y masivamente. Bajo esta premisa, Martín Barbero expone el concepto de "sociedad de masas" refiriéndose a la creación de una sociedad más homogénea bajo los efectos de la industrialización capitalista, y donde "queda la denominación de popular atribuida a la cultura de masa operando como un dispositivo de mistificación histórica, pero también planteando por vez primera la posibilidad de pensar en positivo lo que les pasa culturalmente a las masas" (1987: 47). El autor propone la necesidad de incluir en el estudio de lo popular no solo aquello que culturalmente producen las masas, sino también lo que consumen. Siguiendo la premisa de la sociedad de masas, Martín Barbero (1987) analiza la obra de Walter Benjamin y de Adorno y Horkheimer, separando la idea de "industria cultural" de los segundos con respecto a la degradación de la cultura bajo la industria de la diversión, y la idea de Benjamin, apoyada en la de Carlo Ginzburg, investigan la dinámica cultural para estudiar no el proceso de constitución de lo popular, sino la configuración a la que ha llegado esa cultura y sus modos de expresión (1987: 75), para poder ver por primera vez a la cultura popular desde adentro y no como una degradación de lo masivo. 
Según Martín Barbero, la cultura popular que va del siglo XVIII al XIX es contrahegemónica. Existe una "rebeldía en nombre de la costumbre" (1987: 83). Los años 70', de la mano de Gramsci supusieron un:

proceso de dominación social ya no como imposición desde un exterior y sin sujetos, sino como un proceso en el que una clase hegemoniza en la medida en que representa intereses que también reconocen de alguna manera como suyos las clases subalternas". (Martín Barbero, 1987: 85)

Y que la especificidad de "lo popular" debe verse en las prácticas realizadas en los sectores populares. Entrando al siglo XIX, Martín Barbero (1987) menciona que:

Con la formación de las masas urbanas se produce no sólo un acrecentamiento del conjunto de las clases populares, sino la aparición de un nuevo modo de existencia de lo popular: la desarticulación del mundo popular como espacio de lo otro, de las fuerzas de negación del modo de producción capitalista. (p.171)

En donde "lo popular" pueda ser pensado desde una existencia positiva capaz de desarrollo. Aquí el autor propone, desde lo popular, la figura del "sujeto político" que revaloriza y mediatiza las articulaciones con la sociedad civil; y finaliza su análisis diciendo que "pensar lo popular desde lo masivo no signifique, no deba al menos significar automáticamente alienación y manipulación, sino unas nuevas condiciones de existencia y de lucha, un modo nuevo de funcionamiento de la hegemonía" (1987: 249). 
A partir del planteamiento de Martín Barbero sobre "lo popular" y su relación con las mediaciones, Mattelart (2014) sostiene que formó parte de los debates típicos de la década de los años noventa y que, tanto en "De los medios a las mediaciones" como en sus artículos, Martín Barbero resalta la autonomía de la cultura y también un cierto olvido, precisamente, de esas dos dimensiones debido al exceso de atención sobre la hegemonía. También, según Mattelart (2014) esto se produjo por un cambio en los enfoques teóricos de las investigaciones centrándose durante ese período en los medios y en las mediaciones con las consecuencias ya mencionadas. Estas consideraciones Mattelart las realiza sumando las investigaciones de Néstor García Canclini y de Martín Barbero durante el período mencionado a quienes denomina como parte de la "corriente latinoamericana de los estudios culturales". En definitiva, el problema para Mattelart (Op.cit.) es el desplazamiento del estudio de los medios hacia el de las medicaciones que, consideradas como infinitas por Gramsci, lleva a pensar en una multiplicidad de actores sociales y reemplaza los conceptos de clase, contradicción y conflicto sociales por los de "vínculos sociales".

En oposición a la mirada de Mattelart, podemos ubicar a trabajos como el de Thomas Tufte (2015) que se aproxima a la comunicación popular para desentrañar problemáticas y dinámicas del siglo XXI. A partir de términos como el de "participación", "empoderamiento" o "desarrollo", el autor redefine lo popular para hablar de "comunicación para el cambio social" o como una variante de la "comunicación para el desarrollo", en busca de generar herramientas prácticas de las corrientes teóricas explicadas hasta el momento. El autor continúa con la idea transversal de que la comunicación en las clases populares (o Tercer Sector) es necesaria para impulsar demandas y necesidades desde la capacidad de agencia de movimientos sociales flexibles y heterogéneos ${ }^{2}$. Es en ese intrincado espacio donde se ubica parte de la disputa en torno al uso de las nociones de "lo popular" en García Canclini y Martín Barbero, y de "lo alternativo" en quiénes deberían

2. En la misma línea, se pueden sumar trabajos similares del autor como el escrito junto a Gumucio-Dagron: GUMUCIO, A. \& TUFTE, T. (2008). Raíces e importancia. Introducción a la Antología de Comunicación para el Cambio Social. En GUMUCIO, A. \& TUFTE, T. (2008), Antología de Comunicación para el Cambio Social: Lecturas Históricas y Contemporáneas (p. 16-45). La Paz, Consorcio de Comunicación para el Cambio Social. 
incorporar a Gramsci sin perder el legado marxista tradicional y sus categorías. Resulta igualmente debatible esta aproximación del autor belga porque es una lectura algo reticente a la tradición latinoamericana y que no abarca la relación que lo popular ha tenido con lo alternativo en América Latina (Op.cit.). No acordamos con Mattelart al afirmar que las relaciones de poder y contrapoder se diluyen en las lecturas latinoamericanas, en realidad, a través de la tensión entre lo popular, lo comunitario y lo alternativo se resignifican y revelan la complejidad de nuestras condiciones materiales de existencia, así como de nuestros ámbitos culturales en los cuales se insertan estas tensiones que se extienden a la relación con los medios de comunicación y, a su vez, por esto mismo se modifican.

\section{Antecedentes y debates sobre "lo alternativo"}

Los planteamientos precedentes sobre lo popular permiten pensar cómo lo alternativo está ligado, en parte, a otra matriz teórica y metodológica, es decir, posee diferencias epistemológicas respecto de lo popular y radica en las lecturas sobre el marxismo y los movimientos sociales y políticos propios de América Latina. Lo alternativo, sin embargo, también presenta fronteras difusas en su definición.

Para Armand Mattelart (2014) la concepción de la "alternativa popular" para los medios de comunicación es deudora de los reclamos por el movimiento de trabajadores y otros de tipo popular (participación ciudadana) identificada con su trabajo durante su estancia en Chile en el gobierno de Salvador Allende en los años 70'. La visión de Mattelart sobre el tipo de comunicación popular y/o alternativa está también marcada por su exilio en México y por la traducción que él y Héctor Schmucler hicieron del Informe MacBride (1980). 
Mattelart expresa la noción de la alternativa (revolucionaria) en todos los ámbitos provenientes como opuesta a "los sistemas técnicos de la sociedad productivista" (Op.cit.: 64), ya sea desde el cine con el objetivo de registrar la vida cotidiana de las clases populares (específicamente del cine chileno realizado durante la época de la Unidad Popular, 1970-73). En el sentido de una concepción de una alternativa radical, son poco los medios hoy que podrían caracterizarse como alternativos.

La comunicación alternativa pareciera aún más difícil de definir que la popular y la comunitaria pero sin embargo no dependería de ninguna estructura partidaria, al menos en la visión de Mattelart (2014), sino más bien de movimientos y organizaciones civiles de izquierda alejadas de los partidos marxistas tradicionales, y a veces, inclusive, en su perspectiva de la tendencia guevarista que los llevaría a una concepción foquista que impediría o dificultaría la creación de este tipo de agrupaciones o frentes. Es inevitable que, aunque parezca perderse la discusión sobre qué es la comunicación alternativa, el mismo intento de definirla nos lleva a tratar la cuestión sobre qué lugar y qué concepciones tiene la izquierda y el marxismo en particular sobre los medios de comunicación.

Freire, también, descree del discurso pragmático (Streck, Redin \& Zitoski, 2010: 334-335) y como Mattelart lo asocia al capitalismo, por lo que la comunicación alternativa no estaría sustentada o no sería tal por medio de la práctica. Para el autor brasileño es la educación la forma de construir visiones alternativas y caminos propios ajenos a la lógica mercantil y revertir "los procesos de domesticación de la industria cultural y su búsqueda de homogeneización" (Op. cit.: 350). La educación sería en este caso la clave, como en el anterior lo eran los movimientos de masas clasistas, para poder crear sistemas de comunicación que cuestionen y jaqueen la lógica hegemónica (Op.cit., 2010: 258). 
Siguiendo con la lógica de Mattelart y Graziano, Simpson Grinberg (1986) en primer lugar da cuenta de dos grandes vertientes en lo que es la comunicación alternativa. La primera la define como "la comunicación alternativa como respuesta a la estructura transnacional" (p.7), en tanto a un paradigma comunicacional alternativo en respuesta a lo "intrínsecamente unidireccional y autoritario de los medios masivos" que obstaculiza los procesos democráticos y participativos de comunicación. La segunda vertiente tiene que ver con la "hegemonía de las vanguardias político-intelectuales", dando cuenta de las élites político-intelectuales que denotan el saber teórico e histórico impuesto, como por ejemplo, la teoría gramsciana.

En el primer caso expuesto, Simpson Grinberg (1986) posiciona a la comunicación alternativa no solamente como "un antídoto frente a las estructuras transnacionales, sino una propuesta y un proyecto que cuestiona la concentración del poder comunicacional independientemente de las razones que aduzcan para legitimarlo" (1986: 12). En el segundo apartado, si bien no menciona el término "contrahegemonía", como la mayoría de los autores que tratan a la comunicación alternativa, expone autores como Marx, Engels y Gramsci, entre otros, en torno a su rol intelectual de crítica a la Hegemonía, se trata de dar cuenta de la comunicación alternativa en "el ejercicio de la democracia comunicacional directa, al margen de todo control y sin necesidad de intérpretes privilegiados del sentir colectivo" (p.14).

La reflexión que hace Simpson Grinberg (Op.cit.) nos parece sumamente pertinente y esclarecedora para el estudio de la comunicación alternativa en tanto "el intento de trascender los estereotipos y los tabúes que durante muchos años han constituido gravísimos obstáculos para la intelección más profunda de nuestra realidad y para la formulación de opciones" (p.15). A continuación, el autor invita a abandonar la "fascinación por los medios masivos y las ideas acríticas acerca de su aparente omnipotencia en la formación de conciencia colectiva" (p.17). Pudiéndose acercar a las experiencias populares propiamente dichas, sus canales y redes de comunicación. 
La variedad de significaciones de los conceptos de la comunicación alternativa, así como la popular, fue expuesto por Regina Festa en los años 80' al recabar una variedad de denominaciones que se designaban como alterativa, liberadora dialógica, participativa de base, de los oprimidos horizontal y emergente de resistencia, entre otras (Cogo, 2001: 30).

Algunas de las dificultades para abordar el concepto de comunicación alternativa fue señalado por Rosa María Alfaro (2000), quien aunque utiliza de forma indistinta los términos comunicación popular y comunicación alternativa señala que las dos deberían estar enlazadas con la política, la participación y la ciudadanía (Op.cit., 2000: 4). Por lo cual la autora deja entrever que existe una diferenciación. Además, advierte que si la encuentran en oposición al entretenimiento, a pesar de que lo alternativo y lo popular supongan horizontalidad (ídem), Alfaro reconoce "un primer deslumbramiento de la concepción popular tomada de Freire" pero luego se observa una ruptura en los vínculos de ésta con la educación, la política, la militancia y la cotidianidad (Op. cit., 2000: 5-7). Esa primera fascinación, tal vez, en América Latina provocó el aglutinamiento de algunos sectores y autores entre lo popular y lo alternativo, tal vez dificultando la independencia del segundo término fuera de la matriz marxista. Lo anterior sería factible extendiendo la lectura realizada por Alfaro a la carencia sobre la definición de lo alternativo y, en particular, de la comunicación alternativa. Si la comunicación popular y alternativa se había distanciado de la política, lo habían hecho a merced de los comunicadores para los cuales la autora reclama la aceptación de la tensión entre "[...] realidad y utopía, entre ciudadanía y democracia" (Op.cit., 2000: 14-16). En esta línea podríamos situar a Martín Barbero al decir que lo alternativo está en la participación y a Mata que concluye sobre la inutilidad de las polémicas en torno a la comunicación popular y alternativa debía ser o no masiva comunitaria. Aparece, nuevamente, una supuesta identidad entre lo comunitario y lo alternativo por oposición a lo masivo, sería esta dualidad, también la que impediría la precisión del concepto, o bien, recabar información en profundidad a partir de los usos nativos en busca de su construcción. Esos sentidos que no siempre están tan alejados de la teoría aunque surja el problema de la ruptura epistemológica para definir de qué hablamos cuando nos referimos a lo alternativo. 
Entonces la línea que mencionamos con anterioridad tiene una matriz teórica y epistemológica distinta a aquella que solventaron Mattelarty Graziano. Sobre esta podemos incorporar el aporte de Prieto Castillo (1984) que desde el marxismo pensó que lo alternativo se opone antes que a lo masivo, al autoritarismo y a la lógica dominante, y extiende la concepción de la dimensión alternativa a "productos" y "discursos comunicacionales" (1984: 654). Por otro lado, surgen perspectivas como la de Claudia García (2012) que retoman lo reflexionado sobre lo alternativo por Freire y Alfaro (a la vez retomado de Mattelart), para exponer el concepto de "comunicación para el desarrollo" respecto a una perspectiva comunicacional más consolidada como la acción ${ }^{3}$. García, junto a Rodríguez Bohórquez (2011), también mencionan que la "comunicación alternativa" como tal, funciona como espacio interdisciplinar pionero en programas sociales de la región proveniente del aporte de la teoría crítica de la Escuela de Frankfurt, que deriva a su vez en nuevas propuestas en el ámbito de la "comunicación para el desarrollo", en busca de tensionar las estructuras políticas y económicas en procesos comunicacionales de sectores que no son tenidos en cuenta por los medios de comunicación hegemónicos.

Graziano (1980) fundamenta las bases para una definición de la práctica social, la comunicación alternativa, con supuestos semejantes a los de Mattelart sobre la necesidad de una transformación revolucionaria de la estructura social en su totalidad compleja (en el sentido althusseriano) como condición para la existencia de este tipo de vínculo comunicativo. La autora afirma que, en realidad, la comunicación alternativa debe ser asumida como parte del trabajo de los intelectuales ligados a la militancia y de los cuadros de las organizaciones políticas. En ese sentido, es la movilización, la preparación teórica y la praxis los que garantizarían la existencia de un tipo de comunicación horizontal y participativa. Estas últimas dependen de la movilización de las bases y de los intelectuales para crear estrategias y modalidades alternativas al poder. En definitiva, si bien, la posición de Graziano está más inserta en la tradición marxista leninista y althusseriana, la construcción de un nuevo tipo de hegemonía es también para esta

3. La autora se apoya, además de en el concepto de "comunicación para el desarrollo", en el de "mediaciones" de Jesús Martín Barbero (1987) para dar cuenta del paso de la comunicación alternativa a la comunicación para el desarrollo. 
autora, así como para el intelectual belga, la forma de construir dialógicamente la comunicación alternativa (Op.cit, 1980: 5-6). En ese sentido, Graziano asume para la concepción de lo alternativo una perspectiva doble: toda comunicación es participativa y horizontal retomando a Mario Kaplún (Graziano, 1980: 3) por cual su distinción es innecesaria porque serían condiciones de existencia per se, y por otro, que es antes que una alternativa una "opción", siguiendo a Augusto Chacón (1979, citado por Graziano, 1980) transformadora de una "comunicación alternativa" (Op.cit., 1980: 5). La comunicación alternativa es entonces parte de la lucha política, está subsumida en esta y en la lucha ideológica, así como en la toma de poder para instaurar una nueva lógica en la institucionalidad de los medios de comunicación. Lo precedente supone que la planificación de la comunicación sería uno de los tantos instrumentos y, a su vez, herramientas para lograrlo y sostenerlo. Ese nuevo orden, dista de las recomendaciones vinculadas a la práctica alejada de la teoría, como sostiene Graziano (Op.cit, 1980: 1-4), y de una concepción ingenua sobre la conversión de los ciudadanos, de las bases, en "transmisores" de sentido, si no es cambiando radicalmente el sistema de medios existente. Por esa razón, la comunicación para el desarrollo y para la educación rural no parecieran estar en sintonía con este planteamiento si se mantienen bajo la misma "envoltura ideológica". Para tales exposiciones, Graziano retoma a Armand Mattlelart:

\footnotetext{
[...] frente a la necesidad de vulnerar los medios de comunicación de masas en poder de la clase dominante. Pero parece indiscutible la necesidad de fijar una estrategia que corporice la idea de poder popular y la haga expresándose en la lucha ideológica. (Mattelart 1972, citado por Graziano, 1980: 6)
}

Finalmente, la propuesta de Graziano se resumiría en: “Comunicación alternativa para aquellas relaciones ideológicas de transmisión de imágenes y signos que estén insertas en una praxis transformadora de la estructura social en su totalidad" (Graziano, 1980: 6). En realidad, la autora parte del supuesto de que la comunicación alternativa es parte de la comunicación política y/o al revés. Esta, tal vez, sería una diferencia con los planteamientos más cercanos a perspectivas 
desarrollistas y supuestamente dialógicas que, sin saberlo, como diría Marx, usan los viejos términos para designar un nuevo problema ${ }^{4}$.

Si nos centramos más en el campo mediático, encontramos producciones como la de Vinelli ${ }^{5}$ y Esperón (2004), donde los autores compilan una serie de trabajos que remiten a medios de comunicación que consideran "alternativos". Entre ellos se encuentran producciones de Santiago Gándara (prensa de izquierda), Mariano Zarowsky (documentales), Carlos Aznares (periodismo alternativo) y Fernando Krichmar (Cine), entre otras.

Con la premisa de la crisis institucional Argentina en el año 2001, los autores afirman que desde la denuncia a los grandes medios de comunicación (que llaman "medios de desinformación"), crecen prácticas de comunicación alternativa como "experiencias contrainformacionales, militantes, alternativas, de base y mil denominaciones distintas" (Op.cit., 2004: 5). Como afirman los compiladores en una suerte de introducción es que "lo alternativo" es retomado entre:

La distancia o la vinculación orgánica con los movimientos sociales y políticos; los interrogantes acerca de las formas de gestión; la relación entre emisión y recepción; el testimonio o el protagonismo del periodista militante; la participación popular; las tensiones entre la alternatividad y la masividad, la legalidad y la ilegalidad, la política y la estética y la información y la contrainformación; el uso instrumental de los medios y su participación en coyunturas específicas. (Vinelli \& Esperón, 2004: 5.)

4. Nos referimos a quienes aún utilizan las premisas de la UNESCO, los desarrollos de Schramm y de Lazarsfeld, así como de otros miembros de la Mass Communication Research, junto con autores como Freire, Kaplún o Mattelart. Tal confusión es frecuente en quienes trabajan sobre comunicación y desarrollo utilizando la comunicación radiofónica como "herramienta".

5. Tener en cuenta también el trabajo de la autora denominado "La televisión desde abajo" (2014), que marca la historización de la televisión bajo la perspectiva "alternativa" de la comunicación. 
Vinelli y Esperón (Op.cit.) afirman que no van a exponer un mapa de lo "alternativo", porque les sería imposible, pero sí, posiciones alternativas reflejadas en distintos trabajos y que sirvan para el análisis de dicho texto. Los compiladores afirman que se pueden desplegar todo tipo de dicotomías, antes expuestas, siempre en tensión con lo que se cree instituido, pero siempre con el fin de "desmontar la estructura comunicacional de una sociedad y abrir las puertas a la construcción de otra nueva" (Op.cit., 2004: 6); o también, desde el concepto de "contrainformación", derivado de "lo alternativo", suponen un enfrentamiento "no solo contra el discurso oficial sino también contra el orden establecido" (Op.cit., 2004: 12). En un primer acercamiento, Vinelli y Esperón (Op.cit.) afirman que existe una alternatividad material y otra discursiva, dando cuenta de:

\footnotetext{
Un proceso que abarca desde el discurso hasta la organización del medio y las formas sociales en que éste se utiliza, siendo el discurso contrainformacional el elemento que, ya sea como intervención política de urgencia o como reflexión más profunda, manifiesta las necesidades de la coyuntura política y los objetivos de la organización político-social encarnados, a su vez, en la práctica misma del medio. (Vinelli \& Esperón, 2004: 10)
}

Adentrándonos un poco en ese mapa de "lo alternativo" que mencionan Vinelli y Esperón (Op.cit.), y retomando la mirada de Armand Mattelart expuesta en un principio, Nancy Larrañaga y Florencia Saintout (2003), trabajan con una mirada crítica de la comunicación en América Latina y dan cuenta de "lo alternativo" en tanto a poder independizarse de vínculos dominantes necesitando "un cambio social y político" (p.31). Para ello, las autoras exponen la "teoría de la dependencia y la invasión cultural" con respecto a una comunicación vista desde los medios masivos de comunicación, y definen a la comunicación alternativa como aquella "por fuera, al margen, a veces oponiéndose, a los medios masivos de comunicación y sus intereses" (2003, p.39). Bajo el paradigma de 
lo alternativo, Larrañaga y Saintout (Op.cit.) exponen autores como Antonio Pasquali sobre la idea de transformación: "de la negatividad de la crítica hacia la posibilidad de un nuevo ideal revolucionario" (2003: 41), y las ideas de Paulo Freire donde la comunicación ligada a la liberación puede ser retomada desde la alternatividad comunicacional anteriormente planteada.

La idea de enajenación fue otro de los conceptos que en los años 80’ se oponía a "lo alternativo" que desde una concepción binaria de la ideología, era lo opuesto al "sistema". Hegemonía se concebía como ideología dominante y subalternidad como su asunción. La opción para diferenciar otros procesos era referirse a una “comunicación otra" (González, 2011).

Florencia Saintout, en este caso en colaboración con Andrea Varela, escriben en el año 2014 un texto en el que exponen las preocupaciones comunicacionales de un mundo posmoderno, en el que mencionan, entre otras cuestiones, volver a pensar la subalternidad respecto a la celebración de resistencia. Bajo este paradigma, retoman lo alternativo como lo contrahegemónico, pero ya no tanto desde la resistencia, sino para empezar a pensar una "epistemología de la esperanza" (Op. cit., 2014: 113), con el objetivo de poder tomar de una vez posicionamiento desde lo desplazado.

En este apartado pudimos dar cuenta de un acercamiento teórico a lo que pensamos por "alternativo", desde intelectuales enfocados a la praxis social como pueden ser Mattelart o Freire y siguiendo por el camino de la comunicación, en clave alternativa, dimos con producciones que remarcan lo alternativo como otra posibilidad de mediatización que no sea desde los grandes medios hegemónicos. 


\section{Antecedentes y debates sobre "lo comunitario"}

Los debates de la comunicación desde la perspectiva comunitaria se realzan, más que nada en el plano nacional Argentino, en épocas de crisis institucional donde surgen modos de efectuar la comunicación desde territorios más tangibles (locales). Justamente es la clave territorial la que atraviesa y condiciona la perspectiva comunitaria. Expondremos diversos autores o grupos de autores que nos ayudan a comprender diferentes perspectivas de análisis dentro de lo comunitario.

Si bien Mario Kaplún (2002) en “Una pedagogía de la comunicación (el comunicador popular)"6 se enfoca en la práctica educativa sobre el diálogo constructivo, se posiciona en un tipo particular de comunicación que la define desde el marco contextual latinoamericano, ya que menciona a la comunicación comunitaria teniendo en cuenta que:

En América Latina, los hombres y los pueblos de hoy se niegan a seguir siendo receptores pasivos y ejecutores de órdenes. Sienten la necesidad y exigen el derecho a participar, de ser actores, protagonistas, en la construcción de una nueva sociedad auténticamente democrática. (Op.cit., 2002: 56)

El autor enfatiza que la verdadera comunicación es aquella donde dos o más seres o comunidades intercambian y comparten conocimientos, experiencias y prácticas.

6. Vale aclarar que el texto "Una pedagogía de la comunicación" (2002) es una reedición del libro clásico de Mario Kaplún: "El Comunicador Popular” editado por la CIESPAL en 1985. 
En otro trabajo, Gabriel Kaplún (2007) expone que a la comunicación se le fueron agregando diferentes "apellidos" según el actor social que estuviera involucrado. Entre ellas expone la "comunicación comunitaria" como parte de un proceso de desarrollo local, "que privilegia las estrategias de impulso productivo y social en ese nivel” (p. 313). Gabriel Kaplún menciona que lo comunitario hay que pensarlo desde un cambio social profundo y democrático, en espacios de diálogo y debate. Por otro lado, el autor menciona a la comunicación comunitaria separándola de las dinámicas comunicacionales de los mass media, sino desplegado en una gama de medios más amplia, aunque hace énfasis en el soporte radial.

Krohling Peruzzo enfatiza también en el proceso de democratización de la comunicación y la constitución de un espacio pluralista (2001: 92). Indica una relación estrecha con lo popular: "comunicación popular/comunitaria" según las experiencias de las organizaciones sociales en la constitución de ciudadanía (idem).

Desde la categoría territorial, mencionada al principio, en el manual de comunicación comunitaria llamado "Barrio Galaxia" (2013), escrito por Eduardo Balán, Diego Jaimes, Hernán Alegría y Néstor Borri, remarcan la categoría espacial de la comunicación comunitaria, más específicamente desde lo barrial como:

El intento de darle sentido a los elementos de la comunicación barrial y familiar desde la perspectiva de la posibilidad de la unión, la solidaridad y la organización en el barrio. Está hecha de esos modestos pero permanentes impulsos solidarios en torno a la salúd, la nutrición, la vivienda, la educación, que buscan el encuentro, la "colaboración" de los vecinos, la fiesta y el trabajo. (Balán, Jaimes, Alegría \& Borri, 2013: 21) 
Dicho manual hace énfasis en la comunicación comunitaria trabajada desde los intereses, problemas, necesidades e inquietudes de los sectores populares en un terreno de disputa política. Desde una diferenciación en cuanto a objetivo de los medios masivos de comunicación, separan a la comunicación comunitaria donde el consumo no es clave, sino más bien "interlocutores críticos, solidarios y activos" (2013: 31).

María Cristina Mata (2009) expone la comunicación comunitaria desde proyectos concretos, pero primero menciona que dicha comunicación se define desde la existencia de dos tipos de horizontes: la primera respecto a "una cantidad de experiencias y de prácticas de comunicación que se caracterizan a sí mismas como orientadas a fortalecer ciertos lazos comunitarios" (2009: 23), y otra, que tiene un horizonte planteado como meta o desafío, más allá de lo que sucede estrictamente en la comunidad, sino más bien con algo que los excede pero les otorga sentido y proyección.

Mata (Op.cit.) menciona que desde el campo político-cultural siempre se dijo la necesidad de reconstruir los viejos lazos comunitarios, y con esto se refiere a la capacidad de convocatoria y participación social en los espacios e instituciones que lo constituyen como actores de la vida en común (2009: 25). A partir de esto, la autora afirma que la noción de "comunicación comunitaria" viene a sustituir a la de "comunicación popular" y la de "comunicación alternativa". Aunque sea un debate aún no saldado, la autora se refiere a lo comunitario, la comunidad, desde un agrupamiento de personas con valores, significados y expectativas compartidas. Según Mata (Op.cit.), el error está en afirmar que ese compartir es consensuado, lo comunitario no puede ser visto como un paraíso sin conflictos. Teniendo en cuenta que la comunidad es parte de un contexto mayor: "La comunicación comunitaria debe ser un espacio de integración de diferentes grupos. No solo de 
grupos de la misma comunidad sino de personas e instituciones que, situadas en distintos lugares, pueden compartir un mismo horizonte político" (2009: 29). Un aspecto destacable que marca Mata (Op.cit.) es que "la comunicación comunitaria busca espacios de articulación con otras instancias mayores de comunicación de diversos modos" (2009: 30), dando cuenta de una red discursiva mucho mayor que en la que se encuentra inserta. En el mismo libro ("Construyendo Comunidades"), seguido al texto de Mata expuesto anteriormente, Jorge Huergo (2009) comienza su trabajo definiendo el campo de la comunicación comunitaria y popular, que si bien no se centra puramente en lo comunitario, como venimos trabajando, remarca una idea que nos parece fundamental destacar: la de poner en el eje de la discusión al territorio, como "producto del diálogo que establecemos con una comunidad de la cual formamos parte, aunque a veces solemos abstraernos de ella" (Op.cit., 2009: 38).

Siguiendo con el mismo libro, nos parece pertinente rescatar la intervención de Washington Uranga (2009), en el sentido que toma a lo comunitario contrario a lo masivo afirmando que:

La comunicación comunitaria nos invita a reconstruir la narrativa de la historia desde los procesos comunicacionales que permiten tejer los hechos entre sí, lo cual supone hilvanar la historia particular de cada uno de los actores sociales desde la narrativa política, social y cultural de la historia colectiva. (p.178)

Donde la comunicación comunitaria va más allá de los medios, sino lo que se pueda generar con los mismos como herramientas comunicacionales.

Sobre la lógica que venimos mostrando, Uranga (Op.cit.) destaca la necesidad de contextualizar la comunicación comunitaria desde el territorio, pero lo menciona como "espacio público", de construcción política, como lugar de derechos y reconocimiento tangible de los mismos, donde la comunicación comunitaria 
pueda funcionar efectivamente como facilitador y constructor de ese espacio público. Esa construcción, el autor afirma que es parte de una lucha por el poder de la que no se puede escapar. Según Uranga (Op.cit.), su perspectiva "de comunicación comunitaria no podrá prosperar si no somos capaces de diseñar estrategias comunicacionales que vayan aportando a la construcción de políticas de comunicación elaboradas desde el Estado con la participación de actores sociales diversos" (2009: 183). Supone dar cuenta de un contexto más amplio de inserción con sus dinámicas y movimientos específicos.

Podemos dar cuenta así de varias perspectivas en torno a la comunicación comunitaria, con un eje anclado en lo territorial visto desde diferentes puntos de vista teniendo en cuenta que ese territorio es también un espacio de interrelaciones sociales dinámicas y participativas.

\section{Cruces y conclusiones}

Como mencionamos en la introducción, el objetivo de retomar lo popular, lo comunitario y lo alternativo en el campo de la comunicación tiene su raíz en la polisemia de dichos conceptos y la utilización de los mismos para definir diversos procesos comunicacionales en la esfera social. Así como dimos cuenta de autores que trabajan específicamente cada concepto, podemos dar cuenta de otros que entrecruzan lo popular, lo alternativo y lo comunitario, reforzando nuestra idea de hacer foco en esos tres conceptos.

Habíamos adelantado, también, que otro tipo de cruces se producen a partir de la amplitud del "subcampo" de la Comunicación y la Cultura o, bien, Comunicación/ Cultura. En este caso, también encontramos la utilización como sinónimos aunque el prefijo "y" implica distancia, separación, pero unión en la diferencia; sin embargo, la "/" designa cierto nivel de equivalencia y de conjunción que, más bien, marca la codependencia (Schmucler, 1982). Tal vez, retomar con mayor 
fortaleza los trabajos teóricos sobre el campo de la "Comunicación y la Cultura” o la "Comunicación/Cultura" permitiría recuperar de forma más clara las distinciones entre comunicación comunitarias, popular o alternativa.

Los tres conceptos analizados dan cuenta de diversas perspectivas de análisis que responden al entrecruzamiento entre los tres tipos de comunicación. Si bien en el campo de la comunicación popular hemos encontrado un bagaje intelectual más nutrido, la comunicación alternativa está marcada por un momento histórico en el que el paradigma dominante estaba vinculado a pensar la dualidad entre hegemónico y subalterno; mientras que las concepciones comunitarias remiten a experiencias específicas y a una dimensión del análisis más situado en lo local. Ciertamente no nos basta este trabajo para dar cuenta de todas las posiciones existentes, pero sí creemos haber expuesto un recorrido lo suficientemente abarcativo para dar cuenta de una aproximación inicial a dichos conceptos y a distintos autores/perspectivas que puedan abrir a otras reflexiones para seguir ampliando un campo teórico en constante movimiento. 


\section{Bibliografía}

- ALFARO, R. M. (2000). Culturas populares y comunicación participativa: en la ruta de las redefiniciones: ALFARO, R. M. (Asociación de Comunicadores Sociales). Razón y Palabra, (18): México, 2000. Recuperado de http:// www. razonypalabra.org.mx/ anteriores/n18/18ralfaro.html, mayo-julio 2000.

- BALÁN, E., JAIMES, D., ALEGRÍA, H. \& BORRI, N. (2013). Barrio Galaxia. Manual de la comunicación comunitaria, Ciudad de Buenos Aires, Argentina: Centro Nueva Tierra.

- BOURDIEU, P. (1999). La distinción (La elección de lo necesario). Madrid: Ed. Taurus.

- COGO, D. (2001). La pluralidad como desafío a la comunicación de los excluidos en Brasil y en Latinoamérica. Revista Diálogos, (58). Lima: Federación Latinoamericana de Facultades de Comunicación Social (FELAFACS).

- DUBRAVCIC, M. (2002). Comunicación popular: del paradigma de la dominación al de las mediaciones sociales y culturales. Quito, Ecuador: Ediciones Abya-Yala.

- ESPERÓN, C. \& VINELLI, N. (2004). Contrainformación. Medios Alternativos para la comunicación política. La Plata, Argentina: Editorial Corriente.

- FREIRE, P. (2005). Pedagogía del oprimido. México: Siglo XXI editores. Traducción de Jorge Mellado.

- GARCÍA CANCLINI, N. (1983). ¿De qué estamos hablando cuando hablamos de lo popular? Culturas populares e indígenas. Diálogos en acción, primera etapa. 2004, 153 - 165. 
- GARCÍA, C. (2012). Comunicación y desarrollo en América Latina, temas y problemas de comunicación. Publicación del Departamento de Ciencias de la Comunicación y del Centro de Investigaciones en Comunicación (CICOM), Facultad de Ciencias Humanas, Universidad Nacional de Río Cuarto. Río Cuarto, Argentina, 14, 47- 60.

- GARCÍA, C. \& RODRIGUEZ BOHÓRQUEZ, L. (2011). Sobre profesiones, prácticas y oficios de la comunicación. Revista Signo y Pensamiento (59), 298 306.

- GONZÁlEZ, J. (2011). "Prólogo" en Krohling Peruzzo,C; Tufte, T.; Vega Casanova, J. Trazos de una otra comunicación. Prácticas comunitarias, teorías y demandas sociales. Barranquilla: Editorial Universidad del Norte / Asociación Latinoamericana de Investigadores en Comunicación (ALAIC), xiv-xiv.

- GRAZIANO, M. (1980). Para una definición alternativa de la comunicación. Revista INNINCO. Universidad Central de Venezuela. Tercer Trimestre de 1980, 1-6.

- GRIGNON, C. \& PASSERON, J. (1989). Lo culto y lo popular: miserabilismo y populismo en la sociología y en la literatura, (Capitulo III). Buenos Aires, Argentina: Nueva Visión.

- HUERGO, J. (2009). Algunos desafíos de la comunicación/educación comunitaria y popular en Construyendo Comunidades. Reflexiones actuales de la comunicación comunitaria. Buenos Aires, Argentina: Ed. La Crujía, 37- 49.

- KAPlÚN, G. (2007). La Comunicación Comunitaria. Buenos Aires, Argentina: Anuario de Medios, 311- 320. 
- KAPLÚN, M. (2002). Una pedagogía de la comunicación "el comunicador popular". La Habana, Cuba: Editorial Caminos.

- KROHLING PERUZZO, C. (2001). Comunicación comunitaria y educación para la ciudadanía. Signo y Pensamiento, (38), (XX), Universidad Javeriana: Departamento de Comunicación, 82 - 93.

- KEJVAL, L. (2009). Truchas. Los proyectos político-culturales de las radios comunitarias, alternativas y populares. Buenos Aires, Argentina: Prometeo.

- MARTÍN BARBERO, J. (1987). De los medios a las mediaciones. Comunicación, cultura y hegemonía. Barcelona, España: Gustavo Gilli.

- MATA, M. C. (2009). Comunicación comunitaria en pos de la palabra y la visibilidad social en Construyendo Comunidades. Reflexiones actuales de la comunicación comunitaria. Buenos Aires, Argentina: Editorial La Crujía, 21 - 37.

- MATA, M. C. (1988). Radios y públicos populares. Diálogos de la Comunicación, (19), Córdoba, Argentina.

- MATTElarT, A. (2014). Por una mirada-mundo. Conversaciones con Michel Sénécal. Un recorrido por la trayectoria de uno de los grandes teóricos de la comunicación y la cultura. Barcelona, España: Gedisa.

- PRIETO CASTILLO, D. (1984). La pasión por el discurso. Carta a estudiantes de comunicación. En TUFTE, T. \& GUMUCIO-DAGRON, A. (2006). Antología de la Comunicación para el Cambio Social. Lecturas históricas y contemporáneas. 
México D. F: Ediciones Coyoacán, 653-655.

- SAINTOUT, F. \& LARRAÑAGA, N. (2003). Abrir la comunicación. Tradición y movimiento en el campo académico. La Plata, Argentina: Editorial de la Universidad de La Plata (Edulp).

- SAINTOUT, F. \& VARELA, A. (2014). Los saberes académicos en contextos de compromisos. La epistemología del barro. Revista Oficios terrestres, 1 (30). La Plata, Argentina.

- SCHMUCLER, H. (1982). La investigación: Un proyecto de comunicación/cultura. en Memoria de la comunicación. Buenos Aires, Argentina: Biblos, 145-151.

- SIMPSON GRIMBERG, M. (1986). Comunicación alternativa: tendencias de la investigación en América Latina. En SIMPSON GRIMBERG, M. (1986) Comunicación alternativa para el cambio social. México: Premia.

- STRECK, R. \& ZITSKI, J. (2010). Paulo Freire: una breve cartografía intelectual. En REDIN, E. \& ZIKISKI, J. J. (Orgs); STRECK, D. R. (Coord.). Diccionário Paulo Freire. 2da. ed.,: Belo Horizonte. Barcelona, España: Aténtica Editora, 210-421.

- TUFTE, T. (2015). Comunicación para el cambio social. La participación y el empoderamiento como base para el desarrollo mundial. Barcelona: Icaria.

- URANGA, W. (2016). Conocer, transformar, Comunicar. Buenos Aires, Argentina: Editora Patria Grande.

- URANGA, W. (2009). La comunicación comunitaria: proceso cultural, social y político en Construyendo Comunidades. Reflexiones actuales de la comunicación comunitaria. Buenos Aires, Argentina: La Crujía, 179 - 189. 


\section{Biografías}

Licenciado en Ciencias de la Comunicación Social. Becario doctoral en Agencia de Investigación Cientifica (ANPCyT). Doctorando en Comunicación (Universidad Nacional de La Plata, Argentina). Instituto de Investigaciones en Diversidad Cultural y Procesos de Cambio (IIDyPCa), Universidad Nacional de Río Negro (UNRN) y Agencia de Investigación Científica (Argentina).

\section{Felipe Navarro Nicoletti}

fnavarro.nicoletti@gmail.com

http://orcid.org/0000-0003-3214-3009

IIDyPCa/UNRN/ANPCyT (Argentina)

Dra. en Ciencias Sociales. Profesora Asociada e investigadora del Centro de Estudios en Derechos, Inclusión y Sociedad (CIEDIS) en la Universidad Nacional de Río Negro (Argentina).

\section{Paula Rodriguez Marino}

prmarino@unrn.edu.ar

UNRN/CIEDIS (Argentina) 